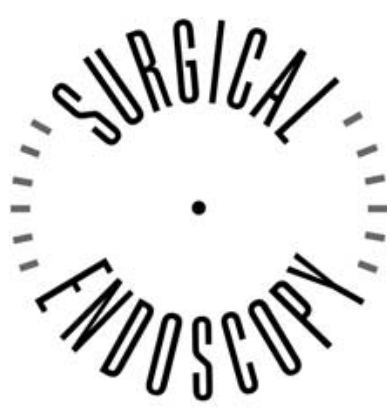

and Other Interventional Techniques

\title{
Laparoscopically assisted transhiatal resection for malignancies of the distal esophagus
}

\author{
W. T. Van den Broek, Ö. Makay, F. J. Berends, J. Z. Yuan, A. P. J. Houdijk, S. Meijer, M. A. Cuesta \\ Department of Surgery, VU Medisch Centrum, Postbus 7057, Amsterdam, The Netherlands
}

[Surg Endosc (2004) 18: 812-817, DOI: 10.1007/s00464-003-9173-y]

The incorrect art for Fig.1 was published in this article. The correct figure is published here.

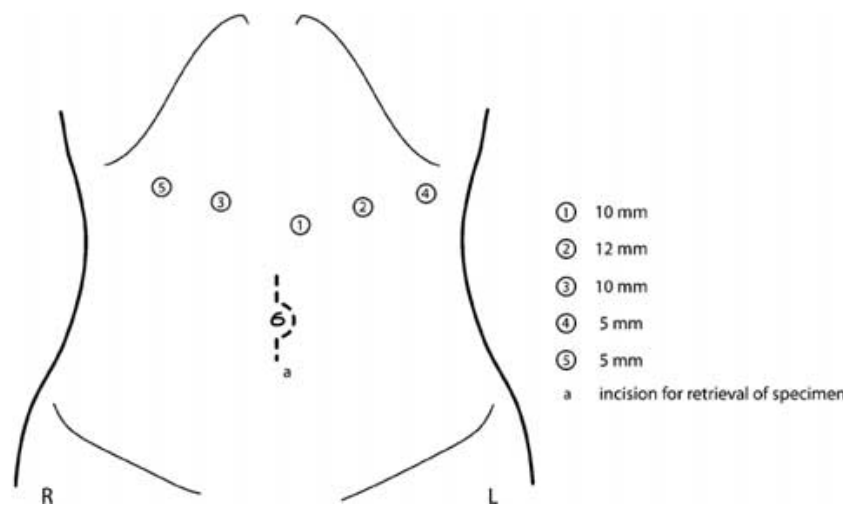

Fig. 1. Trocar placement. 